\title{
Pediatricians' attitude about the use of infant walkers
}

\author{
Semra Kara, M.D. ${ }^{a}$, Ayşe Esra Yttmaz, M.D. ${ }^{a}$, Derya Gumuş Dogan, M.D. ${ }^{a}$, Meki Bilici, M.D. ${ }^{a}$, \\ Sadi Turkay, M.D. ${ }^{a}$, Halise Akca, M.D. ${ }^{a}$, and Ferhat Catal, M.D. ${ }^{a}$
}

\begin{abstract}
Infant walkers are still very popular even though their use might cause injuries. A survey was carried out to obtain information about attitudes and pediatricians' approach regarding the use of infant walkers. Two hundred and forty seven pediatricians who attended the $44^{\text {th }}$ Turkish Congress of Pediatrics and Europediatrics (2008) were invited to reply to a questionnaire prepared by the authors. Two hundred and twenty six questionnaires replied in full were included.

The median age of participants (119 women) was 39 years old (range: $29-58$ years old). Out of the total, $4 \%$ recommended the use of a walker; $32.2 \%$ left the decision to parents' judgment, and $63.7 \%$ did not recommend its use. A hundred and five had previously treated an infant who had an injury associated to the use of the walker; out of them, $73.3 \%$ did not recommend its use and $57.1 \%$ stated that there should be a ban on the sale and manufacture of walkers.

Conclusions. Out of the total number of surveyed pediatricians, $4 \%$ recommend the use of infant walkers and over $30 \%$ leave this decision to parents. Those pediatricians who took care of babies who had an injury associated to the use of a walker were less prone to recommending it.

Key words: walker, pediatrician, child injury prevention.
\end{abstract}

http:/ /dx.doi.org/10.5546/aap.2013.528

\section{INTRODUCTION}

Infant walkers are still very popular in all the world even though they might cause home accidents, burns and poisonings. ${ }^{1,2}$ Parents might consider that walkers are safe because they keep the infant quiet and happy, they provide exercise, promote walking and encourage mobility, and hold the infant during feeding while the mother is able to do household chores..$^{2-5}$

Although the rate of use of infant walkers varies around the world, reported rates are very high: $50 \%$ in the United Kingdom, ${ }^{3} 70 \%$ to $90 \%$ in

a. Department of Pediatrics, Fatih University, School of Medicine, Ankara, Turkey.

E-mail Address:

semrakara@hotmail.com

Conflict of Interest: None.

Received: 12-24-2012

Accepted: 7-29-2013 the United States, ${ }^{6,7} 55 \%$ in Dublin, Ireland, ${ }^{8} 54.5 \%$ in Iran, ${ }^{9} 90 \%$ in Singapore ${ }^{4}$ and $75.4 \%$ in Turkey. ${ }^{1}$ Injuries are associated to the use of walkers in $12 \%$ to $40 \%$ of children who use them. . $^{3,4,10,11}$ Besides, 34 infant walker-related deaths were reported in the United States between 1973 and 1998. ${ }^{11}$ These deaths are usually caused from head injuries when infants fall down the stairs. ${ }^{11}$ There is a four-fold increase of risk of an injury for a fall down the stairways and a two-fold increase of the risk of fracture because of this fall when using a walker. ${ }^{12}$ Considering these risks, the American Academy of Pediatrics recommends a ban on the manufacture and sale of infant walkers,,$^{13}$ as it has happened in Canada since 2004. ${ }^{14}$

From $25 \%$ to $50 \%$ of parents whose children had an injury associated to the use of a walker have continued using it; it is necessary that pediatricians guide parents more convincingly. ${ }^{15-17}$ To our knowledge, there are few studies about pediatricians' attitude in this regard. The objective of the present study was to obtain information concerning pediatricians' attitudes about the use of infant walkers and the approach to this subject with parents.

\section{MATERIAL AND METHODS}

The study included pediatricians that attended the $44^{\text {th }}$ Turkish Congress of Paediatrics held in Istanbul in June 2008. After providing information about the study to all attendees, they were asked to complete the questionnaire of 23 questions prepared by the authors. Pediatricians'age, sex, degree, affiliation and attitudes regarding the use of an infant walker were recorded, reading of scientific papers about the subject, experience in the treatment of patients with injuries associated to its use, and attitudes towards the manufacture and sale of infant walkers.

The study was approved by the Ethics Committee of the School of Medicine of the Fatih University.

Data were analyzed with the Statistical Package for the Social Sciences (SPSS Inc., Chicago, IL, USA.), version 13.0. The $\chi^{2}$ test was used to compare paired or multiple categorical outcome measures. A value of $\mathrm{p}<0.05$ was considered significant. 


\section{RESULTS}

Two hundred and forty seven pediatricians were invited to participate. Questionnaires with incomplete replies were excluded $(n=21)$. Questionnaires corresponding to 226 pediatricians were analyzed. The median age of participants (107 men and 119 women) was 39 years old (range: 29-58 years old). Demographic characteristics of participants are described in Table 1.

Replies to the questionnaire are detailed in Table 2.

Those pediatricians who assisted an infant who had an injury associated to the use of an infant walker support, in a greater proportion than the rest, a ban on the sale and manufacture of walkers (57.1\% versus $24.8 \%, \mathrm{p}<0.001$, Table 3$)$.

Regarding the question: "Do you recommend parents to use an infant walker?" when comparing pediatricians who recommend its use versus those who leave the decision to parents,
TABLE 1. Demographic characteristics of participating pediatricians

\begin{tabular}{lc}
\hline Characteristics & \\
\hline Age, years & 39 \\
Sex & $119(52.6)$ \\
$\quad$ Female & \\
Position & $56(24.8)$ \\
Resident & $138(61.1)$ \\
Specialist & $16(7.1)$ \\
Assistant Professor & $12(5.3)$ \\
Associate Professor & $4(1.8)$ \\
Professor & \\
Affiliation & $76(33.6)$ \\
Private sector & $97(42.9)$ \\
Ministry of Health & $53(23.5)$ \\
University hospital &
\end{tabular}

Data presented as median \pm standard deviation or $\mathrm{n}(\%)$, when applicable.

TABLE 2. Pediatricians' attitudes and approach in relation to the use of infant walkers

\begin{tabular}{|c|c|}
\hline Questions about pediatricians' attitudes and approach & n (\%) \\
\hline \multicolumn{2}{|l|}{ Do you recommend parents the use of infant walkers for their children? } \\
\hline Yes & $9(4)$ \\
\hline Leave the decision to parents after providing an explanation & $73(32.3)$ \\
\hline No & $144(63.7)$ \\
\hline \multicolumn{2}{|c|}{ If you recommend the use of an infant walker, at what age should infants start using it? } \\
\hline 6 months old & $19(23.2)$ \\
\hline 8 months old & $41(50)$ \\
\hline 10 months old & $19(23.2)$ \\
\hline 12 months old & $3(3.6)$ \\
\hline \multicolumn{2}{|c|}{ Should parents be told about the use of infant walkers during follow-up visits? } \\
\hline Yes & $212(93.8)$ \\
\hline No & $14(6.2)$ \\
\hline \multicolumn{2}{|l|}{ Do you read scientific articles about infant walkers? } \\
\hline Yes & $80(35.4)$ \\
\hline No & $146(64.6)$ \\
\hline \multicolumn{2}{|c|}{ Have you ever treated an infant because of an injury associated to the use of an infant walker? } \\
\hline Yes & $105(46.5)$ \\
\hline No & $121(53.5)$ \\
\hline \multicolumn{2}{|l|}{ If you have a child, has your baby ever used an infant walker? } \\
\hline Yes & $73(47.7)$ \\
\hline No & $80(52.3)$ \\
\hline \multicolumn{2}{|c|}{ Do you believe that the manufacture and use of infant walkers should be banned? } \\
\hline Yes & $91(40.3)$ \\
\hline No & $135(59.7)$ \\
\hline
\end{tabular}

Do you think that educating parents about the risks associated to the use of an infant walker will result in a significant decrease in its use?
Yes 
a significant difference was found in previously having treated an infant with an injury associated to the use of an infant walker $(\mathrm{p}=0.016)$. Among those who leave the decision to parents, the rate of pediatricians who had previously not treated any cases was $67.1 \%$ while among those who do not recommend its use, the rate of pediatricians who assisted an infant with injuries associated to its use was $53.5 \%$. On the other hand, there were no significant differences between groups as far as sex, reading of scientific papers about infant walkers and affiliation (Table 4).

\section{DISCUSSION}

In the present study, $63.7 \%$ of pediatricians do not recommend the use of infant walkers and
$32.2 \%$ leave the decision to parents' judgment after providing a relevant explanation. Although only $4 \%$ of pediatricians participating in this study recommend it, the high rate of use $(75.4 \%)$ in Turkey ${ }^{1}$ suggests that a significant number of parents ignore or are not aware of risks, or that pediatricians are not able to provide guidance convincingly.

In spite of warnings against infant walkers, their use and associated injuries continue; for this reason authorities have proposed a ban on their manufacture and sale. Canada was the first country in the world to adopt this measure. ${ }^{14}$ In France, Claudet, et al. ${ }^{18}$ examined 178 hospital admissions to the department of pediatric urgencies due to injuries associated

TABLE 3. Approach of pediatricians who previously treated an infant because of an injury associated to the use of a walker

\begin{tabular}{|c|c|c|c|}
\hline & \multicolumn{2}{|c|}{$\begin{array}{l}\text { Have you ever treated an infant because of an } \\
\text { injury associated to the use of an infant walker? }\end{array}$} & \multirow[t]{2}{*}{$p$} \\
\hline & Yes n $(\%)$ & No n $(\%)$ & \\
\hline \multicolumn{4}{|c|}{ Manufacture and use of infant walkers } \\
\hline Should be banned & $60(57.1)$ & $30(24.8)$ & $<0.001$ \\
\hline Should not be banned & $45(42.9)$ & $91(75.2)$ & \\
\hline Total & 105 (100) & $121(100)$ & \\
\hline
\end{tabular}

TABLE 4. Distribution of pediatricians' replies to the question "Do you recommend the use of infant walkers?" according to different parameters

\begin{tabular}{|c|c|c|c|c|}
\hline & \multicolumn{3}{|c|}{ Do you recommend the use of infant walkers? } & \multirow[b]{2}{*}{$p$} \\
\hline & $\begin{array}{l}\text { Recommend } \\
\qquad \begin{array}{c}(n=9) \\
n(\%)\end{array}\end{array}$ & $\begin{array}{c}\text { Leaves the decision } \\
\text { to parents }(n=73) \\
n(\%)\end{array}$ & $\begin{array}{l}\text { Does not recommend } \\
\qquad \begin{array}{c}(\mathrm{n}=144) \\
\mathrm{n}(\%)\end{array}\end{array}$ & \\
\hline \multicolumn{5}{|c|}{ Treated an infant with an injury associated to the use of a walker } \\
\hline Yes $(n=105)$ & $4(3.8)$ & $24(22.8)$ & $77(73.3)$ & 0.016 \\
\hline No $(n=121)$ & $5(4.1)$ & $49(40.4)$ & $67(55.3)$ & \\
\hline \multicolumn{5}{|l|}{ Sex } \\
\hline Male $(n=107)$ & $6(5.6)$ & $34(31.7)$ & $67(62.6)$ & NS \\
\hline Female $(\mathrm{n}=119)$ & $3(2.5)$ & $39(32.7)$ & $77(64.7)$ & \\
\hline \multicolumn{5}{|c|}{ Have you read scientific articles about infant walkers? } \\
\hline Yes $(n=81)$ & $3(3.7)$ & $21(25.9)$ & $57(70.3)$ & NS \\
\hline No $(n=145)$ & $6(4.1)$ & $52(35.8)$ & $87(60)$ & \\
\hline \multicolumn{5}{|l|}{ Affiliation } \\
\hline Private sector $(n=76)$ & $3(3.9)$ & $26(34.2)$ & $47(61.8)$ & NS \\
\hline Ministry of Health $(n=97)$ & $4(4.1)$ & $28(28.8)$ & $65(67)$ & \\
\hline University hospital $(n=53)$ & $2(3.7)$ & $19(35.8)$ & $32(60.3)$ & \\
\hline
\end{tabular}

NS: not significant. 
to the use of infant walkers during 2 years. Seventy eight percent of those children had fallen down the stairs. The author concludes that the use of infant walkers should be banned in France because it is unsafe and dangerous. Another study conducted in Greece regarding the occurrence of 44/1000 falls per year, 9 every 1000 resulted from the use of an infant walker or were associated to falls from the stairs, and sometimes to severe injuries. ${ }^{19}$ Although infant walkers are less used because of warnings and bans, consequences are still present. ${ }^{20-22}$ Desapriya, et al..$^{23}$ say that the ban on infant walkers is not enough to prevent injuries from occurring; efforts should also be focused on making the population become aware of potential dangers. These authors suggest that parents should be told about infant walkers, especially about the fact that its use is not beneficial for the development of infants.

Apart from parents, all those who participate in the care and development of children should receive information about this issue. Different studies have shown that their level of knowledge is not enough and that evidence-based knowledge is required. ${ }^{24,25}$ Kendrick, et al. ${ }^{25}$ evaluated healthcare agents attitudes and knowledge about the subject and reported that $45.8 \%$ of them agreed with the ban, $13.1 \%$ believed that the use of infant walkers was beneficial, $67.2 \%$ thought that it might delay the onset of gait, and only $1.7 \%$ believed that modern infant walkers were safe for children. They also concluded that most of the healthcare agents had limited knowledge on the subject and did not discuss the rate of injuries associated to its use with parents. Therefore, they suggest that if healthcare agents and midwives knowledge improved, parents update on the subject would also increase. The same authors reported results obtained after training healthcare agents and midwives and concluded that training on injury prevention was associated to more knowledge, more negative attitudes towards infant walkers and a more positive attitude towards parents' and families' education on this subject. Trained midwives were more prone to providing guidance before birth. ${ }^{26}$

To our knowledge, only Rhodes, et al. ${ }^{27}$ evaluated pediatricians' attitudes about infant walkers. They found that an improved knowledge was associated with negative attitudes towards them. In the present study, $90.3 \%$ of pediatricians said that if parents were warned, this would significantly reduce the risk of injuries associated to its use; however, the percentage of pediatricians who read one of the scientific papers about infant walkers was only $35.4 \%$.

It should be considered that $47.7 \%$ of pediatricians use an infant walker for their children. In the study by Rhodes, et al.27 the rate was $36 \%$. While in our study $63.7 \%$ of pediatricians do not recommend the use of infant walkers, Rhodes, et al. ${ }^{27}$ reported that $71 \%$ of pediatricians advised parents not to use them. Particularly in this study, $74.1 \%$ of pediatricians also believed that parents education about risks was probably more beneficial than banning on its sale. Additionally, "knowledge about infant walkers and associated injuries" was a factor that was related to those who always provided guidance about infant walkers. In this study, pediatricians that assisted an infant with an injury associated to the walker were less prone to recommending its use. In view of the above mentioned facts, we consider that the reduction in the use of infant walkers, which is a significant cause of infants' injuries, can be achieved through healthcare agents and pediatricians providing parents evidence based knowledge, and also through the ban on its manufacture and sale.

As a limitation, in our study, a selfadministered questionnaire was used which could result in a bias. Additionally, participants were pediatricians who attended the congress held in Istanbul. Therefore, the results of the present study should be taken into account with caution and cannot be generalized.

\section{CONCLUSIONS}

Only $4 \%$ of pediatricians in this sample recommend the use of infant walkers. On the other hand, half the pediatricians who had a child used it. Pediatricians who took care of babies who had an injury associated to the use of a walker were less prone to recommending it.

\section{REFERENCES}

1. Dogan DG, Bilici M, Yilmaz AE, Catal F, Keles N. Baby walkers: a perspective from Turkey. Acta Pædiatr 2009; 98(10):1656-60.

2. Kendrick D, Marsh P. Baby walkers: prevalence of use and relationship with other safety practices. Inj Prev 1998; 4(4):295-8.

3. Thein MM, Lee J, Tay V, Ling SL. Infant walker use, injuries, and motor development. Inj Prev 1997;3(1):63-6.

4. Bar-on ME, Boyle RM, Endriss EK. Parental decisions to use infant walkers. Inj Prev 1998;4(4):299-301.

5. Stoffman JM, Bass MJ, Fox AM. Head injuries related to the use of baby walkers. Can Med Assoc J 1984;131(6):573-5.

6. MarcellaS,McDonaldB. Theinfantwalker:an unappreciated household hazard. Conn Med 1990;54(3):127-9. 
7. Use of infant walkers. Board of Trustees, American Medical Association. Am J Dis Child 1991;145(8):933-4.

8. Laffoy M, Fitzpatrick P, Jordan M, Dowdall D. Attitudes to and use of baby walkers in Dublin. Inj Prev 1995;1(2):109-11.

9. Shiva F, Ghotbi F, Yavari SF. The use of baby walkers in Iranian infants. Singapore Med J 2010;51(8):645-9.

10. Kendrick D, Ilingworth R, Woods A, et al. Promoting child safety in primary care: a cluster randomized controlled trial to reduce baby walker use. Br J Gen Pract 2005;55(517):582-8.

11. American Academy of Pediatrics. Committee on Injury and Poison Prevention. Injuries associated with infant walkers. Pediatrics 2001;108 (3):790-2.

12. Khambalia A, Joshi P, Brussoni M, Raina P, et al. Risk factors for unintentional injuries due to falls in children aged 0-6 years: a systematic review. Inj Prev 2006;12(6):378-81.

13. MackKA, Gilchrist J, Ballesteros MF. Injuries among infants treated in emergency departments in the United States, 2001-2004. Pediatrics 2008;121(5):930-7.

14. Health Canada. Injury data analysis leads to baby walker ban. [Accessed on March 2013]. Available at: http:/ / www. hc-sc.gc.ca/sr-sr/activ/consprod/baby-bebe-eng.php.

15. Atkinson CC. Another baby walker injury victim. Journal of Emergency Nursing 1997;23(4):302-5.

16. Rieder MJ, Schwertz C, Newman J. Patterns of walker use and walker injury. Pediatrics 1986;78(3):488-93.

17. Smith GA, Bowman MJ, Luria JW, Shields BJ. Baby walkerrelated injuries continue despite warning labels and public education. Pediatrics 1997;100(2):E1.

18. Claudet I, Fédérici S, Debuisson C, Laporte-Turpin E, et al.
[Babywalker use (baby-trot, youpala): an unsafe practice] Arch Pediatr 2006;13(12):1481-5.

19. Dedoukou X, Spyridopoulos T, Kedikoglou S, Alexe DM, et al. Incidence and risk factors of fall injuries among infants: a study in Greece. Arch Pediatr Adolesc Med 2004; 158(10):1002-6

20. TrinkoffA,Parks PL. Prevention strategies for infant walkerrelated injuries. Public Health Rep 1993;108(6):784-8.

21. DiLillo D, Damashek A, Peterson L. Maternal use of baby walkers with young children: recent trends and possible alternatives. Inj Prev 2001;7(3):223-7.

22. Shields BJ, Smith GA. Success in the prevention of infant walker-related injuries: an analysis of national data, 19902001. Pediatrics 2006;117(3):e452-9.

23. Desapriya E, Scime G, Subzwari S, Pike I. Prevention of baby-walker-related injury. Lancet 2009;373(9663):545.

24. Woods AJ,Hapgood R, Colier J, KendrickD, etal.Midwives' knowledge of, attitudes to and practice with baby walkers. Midwifery 2003;19(1):63-71.

25. Kendrick D, Illingworth R, Hapgood R, Woods AJ, Collier J. Baby walkers--health visitors' current practice, attitudes and knowledge. J Adv Nurs 2003;43(5):488-95.

26. Woods A, Collier J, Kendrick D, Watts K, et al. Injury prevention training: a cluster randomised controlled trial assessing its effect on the knowledge, attitudes, and practices of midwives and health visitors. Inj Prev 2004;10(2):83-7.

27. Rhodes K, Kendrick D, Collier J. Baby walkers: paediatricians' knowledge, attitudes, and health promotion. Arch Dis Child 2003;88(12):1084-5.

\title{
Mutation characterization in the GATA-1 gene in patients with Down's Syndrome diagnosed with transient abnormal myelopoiesis or acute megakaryoblastic leukemia
}

\author{
Adrián P. Mansini, Biochemist, ${ }^{a}$ Patricia L. Rubio, Biochemist, ${ }^{a}$ Jorge G. Rossi, Biochemist, ${ }^{b}$ \\ Marta S. Gallego, M.D., ${ }^{c}$ Adriana Medina, Technician, ${ }^{a}$ Pedro A. Zubizarreta, M.D., ${ }^{a}$ María S. Felice, M.D. ${ }^{a}$ \\ and Cristina N. Alonso, Biochemist ${ }^{a}$
}

a. Department of Hematology and Oncology.

b. Department of Immunology and Rheumatology.

c. Department of Genetics.

Hospital de Pediatría SAMIC "Prof. Dr. Juan P. Garrahan".

E-mail Address:

Adrián Mansini, Biochemist: adrian_cell@hotmail.com

This study was financed by the National Agency of Scientific and Technological Promotion (Agencia Nacional de Promoción Científica y Tecnológica, FONCyT) and by the Hospital de Pediatría S.A.M.I.C. "Prof. Dr. Juan P. Garrahan."

Conflict of Interest: None.

Received: 2-18-2013

Accepted: 6-11-2013

\begin{abstract}
Patients with Down'sSyndrome have a higher risk of developing acute megakaryoblastic leukemia (AML). Ten per cent of newborn infants with this syndrome have transient abnormal myelopoiesis (TAM), indistinguishable from AML, which generally remits spontaneously. A high incidence of GATA1 gene mutations was described in both groups of patients. Fourteen bone marrow DNA samples (10 ATM/4 AML) were analyzed by PCR and sequencing; these samples were obtained from 13 patients with Down's Syndrome to describe the rate and mutation characteristics of the GATA-1 gene in the studied population and its consequences at a protein level.

Mutations were detected in 10 out of 10 TAM and in 3 out of 4 AML, which at a protein level would result in an early termination codon $(n=5)$, alterations in the splicing site $(n=6)$ or sequence change $(n=3)$. The high rate of GATA-1 gene mutations was confirmed in newborn infants with Down's Syndrome and MAT or AML.

Key words: transient abnormal myelopoiesis, megakaryoblastic leukemia, GATA-1, Down's Syndrome.
\end{abstract}

http:/ /dx.doi.org/10.5546/aap.2013.532 


\section{INTRODUCTION}

Children with Down's Syndrome are more prone to developing acute leukemia, more frequently acute megakaryoblastic leukemia (AML), especially in the two first years of life. ${ }^{1,2}$

Additionally, during the neonatal period, $10 \%$ of children with trisomy 21 have a clonal disorder called transient abnormal myelopoiesis (TAM), indistinguishable from AML, which in most of the cases $(70 \%$ to $80 \%)$ remits spontaneously within the three months of evolution. However, the remaining $20 \%$ to $30 \%$ develop AML, especially during the three first years of life. ${ }^{3}$

The GATA binding protein 1 (GATA-1) gene encodes a $50 \mathrm{kDa}$ transcription activation factor that is critical for the normal development of the ontogenesis of the erythroid and the megakaryocytic lineages. ${ }^{4,5}$ Recently, GATA-1 exon 2 mutations were described in children with Down's Syndrome with either TAM or AML which are undetectable when the disease is in remission. ${ }^{6}$ It is proposed that these mutations participate in TAM or AML development in children with Down's Syndrome and that they do not present in children with Down's Syndrome and other types of acute leukemia nor in patients with AML but without Down's Syndrome. ${ }^{7,8}$
In the present study, results of the study of the GATA-1 gene mutations in patients with Down's Syndrome and TAM/AML admitted to our institution are reported.

\section{REMARKS}

Eighteen patients with Down's Syndrome and TAM or AML were diagnosed and managed in our Department from 2003 to 2012. Fourteen bone marrow samples (10 TAM/4 AML), including two samples of a patient who had TAM and then AML were collected for the present study.

GATA-1 exon 2 and the intronic flanking sequences were analyzed by PCR and sequencing. ${ }^{9}$ Clinical and laboratory data of patients with Down's Syndrome and TAM or AML at the time of diagnosis are detailed in Table 1. Medians and age ranges of studied populations were 9 ( 1 to 41 ) days for patients with TAM and 18 (9 to 27) months for patients with AML.

A patient with TAM developed AML 9 months after having achieved complete spontaneous remission of TAM (cases 6 and 12).

Results of G-banding cytogenetic studies are shown on Table 2. In the patient with TAM who developed AML new cytogenetic abnormalities were found at the time the latter one was diagnosed.

TABLE 1. Clinical and laboratory data of patients with Down's Syndrome and transient abnormal myelopoiesis or megakaryoblastic leukemia at the time of diagnosis

\begin{tabular}{|c|c|c|c|c|c|c|c|c|}
\hline Case & Age $^{*}$ & Diag & Sex & WBC (x109/1) & $\mathrm{Hb}(\mathrm{g} / \mathrm{dL})$ & Plat. (x109/1) & $\begin{array}{c}\text { Liver } \\
\text { enlargement }\end{array}$ & $\begin{array}{c}\text { Spleen } \\
\text { enlargement }\end{array}$ \\
\hline 1 & $4 \mathrm{~d}$ & TAM & M & 45 & 15.1 & 25 & Yes & Yes \\
\hline 2 & $22 \mathrm{~d}$ & TAM & $\mathrm{F}$ & 35.1 & 9.8 & 55 & Yes & Yes \\
\hline 3 & $13 \mathrm{~d}$ & TAM & M & 120 & 16.5 & 186 & Yes & Yes \\
\hline 4 & $9 d$ & TAM & M & 83.6 & 18.8 & 56 & Yes & Yes \\
\hline 5 & $1 \mathrm{~m}$ & TAM & $\mathrm{F}$ & 8.4 & 9.3 & 23 & Yes & Yes \\
\hline $6^{* *}$ & $6 \mathrm{~d}$ & TAM & M & 47.2 & 16.3 & 195 & Yes & No \\
\hline 7 & $40 \mathrm{~d}$ & TAM & M & 57 & 8.7 & 144 & Yes & Yes \\
\hline 8 & $9 \mathrm{~d}$ & TAM & M & 30 & 12.3 & 102 & Yes & Yes \\
\hline 9 & $1 \mathrm{~d}$ & TAM & $\mathrm{F}$ & 40 & 8.5 & 531 & Yes & Yes \\
\hline 10 & $5 d$ & TAM & M & 34.9 & 15.5 & 44 & Yes & Yes \\
\hline 11 & $9 \mathrm{~m}$ & AML & $\mathrm{F}$ & 6.9 & 10.2 & 84 & Yes & No \\
\hline $12^{* *}$ & $11 \mathrm{~m}$ & AML & M & 4.7 & 7.5 & 18 & No & No \\
\hline 13 & $25 \mathrm{~m}$ & AML & M & 9.3 & 4.4 & 23 & Yes & Yes \\
\hline 14 & $27 \mathrm{~m}$ & AML & F & 25.4 & 3.7 & 10 & Yes & Yes \\
\hline
\end{tabular}

WBC: white blood cell count. *Age: d (days), m (months). ** Same patient.

TAM: transient abnormal myelopoiesis. AML: acute megakaryoblastic leukemia. 
Detected mutations are described in Table 3 , including their consequences at a protein level and their classification according to what Kanezaki, et al. proposed. ${ }^{10}$

Eight $(62 \%)$ of the 13 mutations identified in the TAM and AML samples corresponded to insertions/deletions/duplications and 5 $(38 \%)$, to base substitutions. Mutations were detected in all patients with TAM; the types of characterized mutations were duplications $(n=5)$, simple nucleotide substitutions $(n=4)$ and deletion $(n=1)$. In 3 of the 4 patients with AML the presence of duplications $(n=2)$ or simple nucleotide substitution $(n=1)$ were evidenced.

Computational analysis of the consequences of mutations at a protein level revealed the presence of an early termination codon of the translation in 5 samples $(\mathrm{TAM}=4 / \mathrm{AML}=1)$, the loss of exon 2 due to modifications in splicing sites in 6 cases $(\mathrm{TAM}=5 / \mathrm{AML}=1)$ in which mutations involved critical sites of signal recognition (Figure 1). In two cases mutations were translated in a change of the amino acid sequence.

During the evolution of the 10 patients with TAM, 8 achieved complete remission spontaneously without receiving any type of chemotherapy. A patient died before achieving complete remission because of an acute respiratory infection, and one patient was lost to follow-up. Three out of the 8 patients who achieved complete remission remain diseasefree with $+48,+55$ and +90 months of follow-up. Out of the remaining 5 patients who achieved complete remission, one developed AML after 9 months in complete remission, 3 died in complete remission ( 2 cases due to sepsis and 1

FIGURE 1. Schematic representation of exon 2 of the GATA1gene, where the location of the detected mutation sites are pointed out. The symbol indicates the type of outcome at a protein level. Loss of exon 2 because of a splicing error, change in the amino acid sequence, early termination codon of the translation in exon 2 and early termination codon of the translation in exon 3

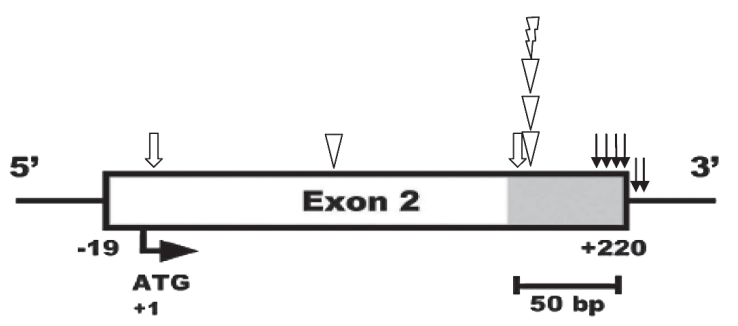

TABLE 2. Result of the cytogenetic studies of the 13 patients with Down's Syndrome and transient abnormal myelopoiesis or megakaryoblastic leukemia in the bone marrow

\begin{tabular}{lcc}
\hline Case & Diagnosis & Karyotype \\
\hline 1 & TAM & $47, \mathrm{XY},+21 \mathrm{c}[20]$ \\
2 & TAM & $47, \mathrm{XX},+21 \mathrm{c}[20]$ \\
3 & TAM & $47, \mathrm{XY},+21 \mathrm{c}[20]$ \\
4 & TAM & $46, \mathrm{XY},-19,+21 \mathrm{c}[3] / 47, \mathrm{XY},+21 \mathrm{c}[14]$ \\
5 & TAM & $47, \mathrm{XX},+21 \mathrm{c}[20]$ \\
$6^{*}$ & TAM & $47, \mathrm{XY},+21 \mathrm{c}[20]$ \\
7 & TAM & $47, \mathrm{XY},+21 \mathrm{c}[20]$ \\
8 & TAM & $47, \mathrm{XY},+21 \mathrm{c}[20]$ \\
9 & TAM & $47, \mathrm{XY},+21 \mathrm{c}[20]$ \\
10 & TAM & $47, \mathrm{XX},+21 \mathrm{c}[20]$ \\
11 & AML & $46, \mathrm{XX},+21 \mathrm{c}, \mathrm{der}(21 ; 21)(\mathrm{q} 10 ; \mathrm{q} 10) \mathrm{c}[20]$ \\
$12^{*}$ & AML & $47, \mathrm{XY},-7,+21 \mathrm{c},+\operatorname{mar}[10] / 48, \mathrm{XY}, \mathrm{idem},+21[6] / 47, \mathrm{XY},+21 \mathrm{c}[4]$ \\
13 & AML & $47, \mathrm{XY}, \mathrm{i}(7)(\mathrm{q} 10),+21 \mathrm{c}[4] / 47, \mathrm{XY},+21 \mathrm{c}[16]$ \\
14 & AML & $46, \mathrm{XY}, \operatorname{der}(15) \mathrm{t}(9 ; 15)(\mathrm{q} 11 ; \mathrm{q} 11.2),-17, \operatorname{add}(19)(\mathrm{p} 13.3), \mathrm{der}(21) \mathrm{t}(17 ; 21)(\mathrm{q} 11.2 ; \mathrm{p} 13),+\operatorname{mar}[16] / 47, \mathrm{idem},+21 \mathrm{c}[4]$ \\
\hline
\end{tabular}

* Same patient.

TAM: transient abnormal myelopoiesis. AML: acute megakaryoblastic leukemia. 
TABLE 3. Summary of the GATA-1 gene mutations in the studied bone marrow samples and predicted outcome at a protein level

\begin{tabular}{|c|c|c|c|c|}
\hline Case & Diagnosis & Mutation* & Outcome of the mutation & Mutation subtype ${ }^{* *}$ \\
\hline 1 & TAM & c.214_218dup & Splicing error & Spl \\
\hline 2 & TAM & c. $5 \mathrm{~A}>\mathrm{G}$ & Glu2Gly & NA \\
\hline 3 & TAM & c.90_91delAG & (Val32Phe) +38 Stop & PTC 1-5' \\
\hline 4 & TAM & c. $220+1 G>A$ & Splicing error & Spl \\
\hline 5 & TAM & c.151_184dup & Tyr62Stop & PTC 1-5' \\
\hline $6 \#$ & TAM & c.150_184dup & Tyr62Stop & PTC 1-5' \\
\hline 7 & TAM & c. $219 A>G$ & Splicing error & Spl \\
\hline 8 & TAM & c.217_220del & Splicing error & Spl \\
\hline 9 & TAM & c. $220+2 \mathrm{~T}>\mathrm{C}$ & Splicing error & Spl \\
\hline 10 & TAM & c.169_184dup + c.184_185insG & Tyr62Trp + 142Stop & PTC 1-3' \\
\hline 11 & AML & c.149_183dup & Tyr62Arg & NA \\
\hline $12 \#$ & AML & c.150_184dup & Tyr62Stop & PTC 1-5' \\
\hline 13 & AML & WT & WT & NA \\
\hline 14 & AML & c. $220 \mathrm{G}>\mathrm{A}$ & Splicing error & Spl \\
\hline
\end{tabular}

* Nucleotide number 1 corresponds to the A of the ATG codon at the onset of the translation located in exon 2 of the GATA-1 gene according to the sequence of reference (NM_002049.3).

** Classification as per Kanezaki, et al. Spl.: splicing error; NA not applicable.

\# Same patient.

TAM: transient abnormal myelopoiesis. AML: acute megakaryoblastic leukemia.

due to heart disease decompensation). A patient was lost to follow-up 31 months ago.

As far as the 4 patients with AML, all achieved complete remission. One of them had an early relapse, a second treatment was administered but died due to infectious complications. The 3 remaining patients live in complete remission at $+22,+46$ and +65 months after their diagnosis.

\section{DISCUSSION}

Hematological disorders associated to GATA-1 gene mutations are evidenced at an early age and therefore the intrauterine origin of these abnormalities, during fetal development, is speculated. This is in accordance with the liver enlargement observed in all the TAM cases analyzed at the time of the diagnosis since the liver plays a fundamental role during fetal hematopoiesis.

The first event or genetic abnormality is the presence of trisomy 21, which predisposes hematopoietic cells to the acquisition of GATA-1 gene mutation that would account for the appearance of the TAM syndrome even though the pathophysiology of the spontaneous remission observed in these cases is unknown.

GATA-1 mutations were detected in all patients analyzed who had been diagnosed with TAM. Concerning the patient with the diagnosis of TAM who had a spontaneous remission and 9 months later developed AML, although the presence of the same mutation was proved in both samples of GATA-1, the cytogenetic test reveals the acquisition of new abnormalities in the leukemic clone. These findings strengthen the theory that both conditions involve the same population of hematopoietic cells and suggest that the progression of TAM to AML could be the consequence of the acquisition of additional mutations.

It is important to consider the age of onset of the clinical condition, a piece of information relevant to the differential diagnosis between TAM and AML, because $80 \%$ of TAM cases remit spontaneously before the first three months of life without the need of a treatment. Even though 
TAM diagnosis is based on the clinical and hematological characteristics of the patient, and mainly on the progress to spontaneous remission, the demonstration of the presence of mutations in the GATA-1 gene by molecular biology techniques could be used to guide the diagnostic suspicion of patients with Down's Syndrome without clinical or hematological manifestations.

Some authors propose the preventive administration of low-dose chemotherapy to patients with $\mathrm{TAM},{ }^{11}$ but morbidity and mortality of these treatments to newborn infants diagnosed with Down's Syndrome should be taken into account and leave the treatment for those infants who have life-threatening clinical complications.

As far as we know, this is the first study conducted in Argentina, study in which GATA-1 gene mutations are characterized in patients with Down's Syndrome diagnosed with TAM and AML. The high rate of mutations found in newborn infants with Down's Syndrome and TAM suggest the convenience of examining for its presence in all the newborn infants with Down's Syndrome so as to individualize those at a higher risk of developing TAM or AML. These latter patients would have to be strictly followed-up from a clinical standpoint than those newborn infants with Down's Syndrome who do not have it, with the aim of making an early diagnosis to avoid the complications related to this condition. Additionally, the serial evaluation of detected mutations would allow to monitor those patients with TAM to check the kinetics of the disappearance of the preleukemic clone and predict an eventual progression to AML at an early stage.

The present study has enabled to confirm the high published rate of GATA-1 gene mutations in newborn infants with Down's Syndrome and TAM or AML., ${ }^{8,10,12}$ The knowledge of these mutations will contribute to a better understanding of these diseases in children with Down's Syndrome which will favor the detection of potential therapeutic targets for future treatment strategies.

\section{REFERENCES}

1. Fong CT, Brodeur GM. Down's syndrome and leukemia: epidemiology, genetics, cytogenetics and mechanisms of leukemogenesis. Cancer Genet Cytogenet 1987;28:55-76.

2. Webb D, Roberts I, Vyas P. Haematology of Down syndrome. Arch Dis Child Fetal Neonatal 2007;92:503-7.

3. Baumann I, Niemeyer CM, Brunning RD, Arber DA, et al. Myeloid proliferations related to Down Syndrome. En: Sdwerdlow SH, Campo E, Lee Harris N, Jaffe ES, eds. WHOClassification of Tumours of Haematopoietic and Lymphoid Tissues. Lyon, France: International Agency for Research on Cancer; 2008. Págs.142-4.

4. Cantor A, Orki S. Transcriptional regulation of erythropoiesis: an affair involving multiple partners. Oncogene 2002;21:3368-76.

5. ShivdasaniRA.Molecularand transcriptional regulation of megakaryocyte differentiation. Stem Cells 2001;19:397-407.

6. Wechsler J, Greene M, Mc Devitt MA, Anastasi J, et al. Acquired mutations in GATA1 in the megakaryoblastic leukemia of Down syndrome. Nat Genet 2002;32:148-52.

7. Ahmed M, Sternberg A, Hall G, Thomas A, et al. Natural history of GATA1 mutations in Down syndrome. Clinical observations, interventions, and therapeutic trials. Blood 2004;103:2480-9.

8. GroetJ,McElwaineS,SpinelliM, RinaldietA, etal. Acquired mutations in GATA1 in neonates with Down's syndrome with transient myeloid disorder. Lancet 2003;361:1617-20.

9. Hitzler JK, Cheung J, Li Y, Scherer SW, Zipursky A. GATA1 mutations in transientleukemia and acutemegakaryoblastic leukemia of Down syndrome. Blood 2003;101:4301-4.

10. Kanezaki R, Toki T, Terui K, Xu G, et al. Down syndrome and GATA1 mutations in transient abnormal myeloproliferative disorder: mutation classes correlate with progression to myeloid leukemia. Blood 2010;116:4631-8.

11. Al-Ahmari A, Shah N, Sung L, Zipursky A, et al. Long-term results of an ultra low-dose cytarabine-based regimen for the treatment of acute megakaryoblastic leukaemia in children with Down síndrome. Brit J Haematol 2006;133:646-8.

12. Alford KA, Reinhardt K, Garnett C, Norton A, et al. Analysis of GATA1 mutations in Down syndrome transient myeloproliferative disorder and myeloid leukemia. Blood 2011;118:2222-38. 